\title{
Four New Factors of Fermat Numbers
}

\author{
By D. E. Shippee
}

Using a System 370, Model 158, IBM Computer, I was able to extend the research of R. M. Robinson [1] and others [2] and [3] concerning the exploration of factors of Fermat Numbers. I wrote my own arithmetic routines to operate on a bit string with a length of 1024 bites (128 8-bit BYTES). Thus, I was able to test possible factors which were larger than the $2^{32}-1$ fixed word maximum.

I tested numbers of the form $K \cdot 2^{n}+1$, where $23 \leqslant n \leqslant 100$ and $3 \leqslant K \leqslant$ $29999, K$ is odd; and $101 \leqslant n \leqslant 256$ and $101 \leqslant K \leqslant 293, K$ is odd. I refound all previously found factors within these ranges, as well as:

$$
\begin{aligned}
697 \cdot 2^{64}+1 & \text { divides } F_{62} \\
7551 \cdot 2^{69}+1 & \text { divides } F_{66} \\
683 \cdot 2^{73}+1 & \text { divides } F_{71} \\
1421 \cdot 2^{93}+1 & \text { divides } F_{91}
\end{aligned}
$$

International Business Machines Corporation

Box 390

Poughkeepsie, New York 12602

1. RAPHAEL M. ROBINSON, "A report on primes of the form $K \cdot 2^{n}+1$ and on factors of Fermat numbers," Proc. Amer. Math. Soc., v. 9, 1958, pp. 673-681.

2. JOHN C. HALLYBURTON, JR. \& JOHN BRILLHART, "Two new factors of Fermat numbers," Math. Comp., v. 29, 1975, pp. 109-112.

3. G. MATTHEW \& H. C. WILliAMS, "Some new primes of the form $K \cdot 2^{n}+1$," Math. Comp., v. 31, 1977, pp. 797-798.

Received October 19, 1977.

AMS (MOS) subject classifications (1970). Primary 10A25, 10A40, 10-04.

Key words and phrases. Fermat numbers, factoring. 